\title{
ЭКОЛОГИЯ
}

DOI: https://doi.org/10.15688/jvolsu3.2017.4.14

UDC $332.1 ; 504.03$

LBC 65.049

\section{EVALUATION OF DEVELOPMENT SUSTAINABILITY AT THE REGIONAL LEVEL: THE CASE OF TATARSTAN REPUBLIC ${ }^{1}$}

\author{
Sergey N. Kirillov \\ Lomonosov Moscow State University, Moscow, Russian Federation \\ Alla A. Pakina \\ Lomonosov Moscow State University, Moscow, Russian Federation \\ Nadezhda I. Tulskaya \\ Lomonosov Moscow State University, Moscow, Russian Federation
}

\begin{abstract}
The development of integrated indicators that take into account economic, environmental and social criteria remains one of the most relevant aspects of evaluating the sustainability of development. Inequality of development leads eventually to lower rates of economic growth and requires a detailed analysis of socio-environmental criteria in their interconnection with economic growth. The coefficient of decoupling is one of the development indicators which reflects economic and environmental aspects of regional development and is widely used today in Russian and foreign practices. The possibility of using this approach is analyzed by the example of one of the most developed regions of Russia - Republic of Tatarstan. The analysis of statistical data on economic development in the number of Middle Volga regions and its influence on the environment allows concluding that the effect of decoupling is typical for all studied regions. At the same time, the differentiation of the coefficient values of decoupling by the administrative districts of Tatarstan has shown the need for further research. The choice of indicators (such as gross regional product, volume of emissions into atmosphere, discharges into water bodies, etc.) for calculating the decoupling $\approx$ coefficient, which reflect the degree of anthropogenic load on natural environment, must be adjusted in accordance to $\underset{\sim}{i}$ the type of regional nature use. Working out the methodological approaches to solution of this problem will facilitate $\therefore$ a more correct evaluation of the decoupling effect, taking into account environmental, economic and social aspects of development to adjust the goals of sustainable development at the regional level.

Key words: sustainable development, sustainability criteria, decoupling effect, Republic of Tatarstan.

УДК $332.1 ; 504.03$

ББК 65.049
\end{abstract}

ОЦЕНКА УСТОЙЧИВОСТИ РАЗВИТИЯ НА РЕГИОНАЛЬНОМ УРОВНЕ: ПРИМЕР РЕСПУБЛИКИ ТАТАРСТАН ${ }^{1}$

Сергей Николаевич Кириллов

Московский государственный университет им. М.В. Ломоносова, г. Москва, Российская Федерация

Алла Анатольевна Пакина

Московский государственный университет им. М.В. Ломоносова, г. Москва, Российская Федерация 


\section{Надежда Игоревна Тульская}

Московский государственный университет им. М.В. Ломоносова, г. Москва, Российская Федерация

Аннотация. Одним из наиболее актуальных аспектов оценки устойчивости развития в настоящее время остается разработка комплексных показателей, позволяющих учесть экономические, экологические и социальные индикаторы. Неравномерность развития, приводящая в конечном итоге к замедлению темпов роста экономики, требует детального анализа на основе сопоставления социальных и экологических критериев развития в их взаимосвязи с экономическим ростом. Одним из индикаторов развития, отражающих динамику экономических и экологических показателей развития, является коэффициент декаплинга, активно применяющийся в последнее время в исследованиях подобного рода в мировой и отечественной практике. Возможность применения такого подхода была проанализирована нами на примере одного из наиболее развитых регионов России - Республики Татарстан. Анализ статистических данных по экономическому развитию ряда регионов Среднего Поволжья и сопутствующему воздействию на окружающую среду позволил сделать вывод о наличии эффекта декаплинга во всех рассматриваемых регионах. В то же время дифференциация значений коэффициента декаплинга по административным районам Татарстана показала необходимость дальнейших исследований. Выбор показателей для расчета коэффициента декаплинга (валовой территориальный продукт, объемы выбросов в атмосферный воздух и сбросов в водные объекты и т. п.), отражающих степень антропогенной нагрузки на природную среду, требует корректировки в зависимости от характера природопользования. Разработка методических подходов к решению этой задачи будет способствовать более корректной оценке эффекта декаплинга с учетом экологических, экономических и социальных аспектов развития для корректировки целей устойчивого развития на региональном уровне.

Ключевые слова: устойчивое развитие, критерии устойчивости, эффект декаплинга, Республика Татарстан.

\section{Введение}

На протяжении четверти века, прошедшей после Конференции ООН по окружающей среде и развитию в Рио-де-Жанейро, одним из ключевых условий реализации принципов устойчивого развития остается разработка критериев устойчивости. Многочисленные международные, национальные и региональные программы, принятые за это время, продемонстрировали необходимость выработки системы индикаторов, позволяющих адекватно оценить достижения и проблемы, возникающие в результате внедрения в практику тех или иных механизмов, нацеленных на переход к устойчивому развитию. Одним из основополагающих международных документов, представляющих безусловный интерес с точки зрения опыта оценки успехов в достижении устойчивого развития, стала инициированная ООН Программа устойчивого развития до 2030 г. (2030 Agenda for Sustainable Development) [20]. В Программе, в частности, были сформулированы 17 Целей устойчивого развития, получивших официальное признание в мировом сообществе. Важной характеристикой этих целей в формулировке принятого документа является их конструктивность и очевидная связь с системой приоритетов российской концепции рационального природопользования: реализация целей предполагает решение социально-эколого-экономических проблем развития общества.

В принятой программе акцентируется внимание на существенных успехах мирового сообщества, достигнутых за период с 1990 по 2015 г. [6]. Согласно документу, во всем мире повысилось материальное благосостояние, утроилось число людей, принадлежащих к так называемому «среднему классу», и сократилось число людей, живущих в условиях крайней нищеты, расширилась сфера здравоохранения и образования, увеличился охват начальным образованием в развивающихся странах и т. п. В то же время еще более остро обозначились различия в уровне развития по странам и регионам мира, что проявляется как в обеспеченности населения стран с разным уровнем развития продовольствием, водой и другими ресурсами, так и в уровне жизни в целом. Однако тенденции усугубления такого неравенства постоянно отмечаются и на уровне регионов внутри стран. В социологических исследованиях приводятся данные, свидетельствующие о том, что для регионов России характерен «избыточный» уро- 
вень неравенства, который приводит к замедлению темпов роста экономики [15]. Не менее существенные различия отмечаются в регионах России в социальной сфере и состоянии окружающей среды. В связи с этим анализ показателей, позволяющих проводить оценку устойчивости развития на основе учета комплекса характеристик, отражающих социальные, экономические и экологические аспекты развития, представляется актуальной задачей, решение которой позволит своевременно выявлять проблемы и корректировать стратегии развития.

\section{Эффект декаплинга как индикатор устойчивости развития}

Проблема выработки критериев устойчивости заняла прочные позиции в междисциплинарных научных исследованиях после Конференции ООН по окружающей среде и развитию 1992 г., на которой была признана основополагающая роль концепции устойчивого развития. Необходимость выработки таких критериев подчеркивалась, например, в основном документе конференции - «Повестке дня на XXI век». Анализ современного состояния проблемы позволяет сделать вывод, что за прошедшую четверть века ситуация изменилась несущественно: многочисленные индикаторы устойчивости развития, разработанные к настоящему времени ведущими научными, финансовыми и политическими институтами $(\mathrm{OOH}$, Всемирный Банк, Организация стран экономического сотрудничества и развития (ОЭСР) и др.), лишь подчеркнули сложность проблемы [6]. Необходимость учета трех различных групп показателей развития, экономических, социальных и экологических которые объективно часто оказываются противоречащими друг другу, привела к тому, что различные службы и институты разрабатывали свои наборы показателей [2]. Тем не менее в современной мировой практике сформировался ряд подходов к разработке интегральных индексов, учет которых позволяет оценить многообразие и сложность комплексной оценки устойчивого развития, адаптировать имеющиеся методики к условиям конкретных территорий и предложить оригинальные варианты их применения. Широко извес- тны такие показатели, как Индекс человеческого развития (Human Development Index), Индекс скорректированных чистых накоплений (Adjusted net savings), разработанные ВВФ показатель «Экологического следа» (Ecological Footprint) и Индекс живой планеты (Living Planet Index) и др.

Важную роль в развитии методологических основ оценки устойчивости развития сыграла относительно новая концепция «зеленой» экономики. Программой ООН по охране окружающей среды (UNEP) было предложено следующее определение: «“зеленая экономика" - такая экономика, которая приводит к улучшению благосостояния человека и социальной справедливости, значительно уменьшая экологические риски и недостаток (дефицит) экологических благ» [22]. Очевидно, что предложенная трактовка напрямую связана с понятием «декаплинга» («decoupling»), широко используемым в качестве ориентира экологической политики на региональном и национальном уровнях. Так, в Стратегии по окружающей среде ОЭСР (Организация экономического сотрудничества и развития) достижение эффекта декаплинга при экономическом росте обозначено как основная цель первой декады XXI в. [7].

Сегодня принцип декаплинга широко используется в комплексных оценках развития, а его изучению посвящено множество работ как российских, так и зарубежных авторов $[1 ; 18 ; 19]$. Под декаплингом понимается расхождение или рассогласование темпов роста благосостояния населения и воздействия на окружающую среду, а наличие эффекта декаплинга означает, что экономический рост сопровождается снижением такой нагрузки [9]. Коэффициент декаплинга рассчитывается как соотношение уровня загрязнения и ВВП (ВРП) в текущем периоде к базовому:

$$
D_{t}=1-\frac{E P_{t}}{D F_{t}} / \frac{E P_{t-1}}{D F_{t-1}}
$$

где $D_{t}$ - коэффициент декаплинга; $E P_{t}$ и $E P_{t-1}-$ показатели, характеризующие негативное воздействие на среду в текущем и базовом периодах; $D F_{t}$ и $D F_{t-1}-$ показатели развития экономики (ВВП, ВРП, объемы производства) в соответствующие периоды. 
Положительная величина коэффициента декаплинга свидетельствует о том, что темпы роста экологической нагрузки демонстрируют тенденцию к снижению по сравнению с темпами роста экономики за тот же период. Для вычисления коэффициента могут использоваться как абсолютные показатели, так и их динамика. Преимущество данного подхода заключается в том, что сопоставление экономических и экологических результатов природопользования не требует введения балльных оценок, как правило, «нивелирующих» некоторые расхождения в абсолютных показателях. Для решения задачи комплексной оценки устойчивости развития, требующей учета различных аспектов (экологических, экономических, социальных), применение такого подхода представляется перспективным как в области экологической экономики, так и других междисциплинарных исследований.

\section{Экологические аспекты экономического роста региона}

Возможность применения изложенного выше подхода была проанализирована на примере одного из регионов Поволжья - Республики Татарстан. Выбор региона исследования обусловлен рядом причин, среди которых: высокий уровень экономического развития и диверсифицированная структура экономики, расположение в чрезвычайно значимом в экологическом отношении регионе бассейна Волги, а также сохраняющееся неравенство в уровне жизни населения. Основные социально-экономические характеристики Республики Татарстан в сравнении с соседними регионами представлены в таблице 1.

Республика Татарстан является безусловным лидером по уровню экономического развития среди перечисленных в таблице субъектов Федерации и занимает ведущие позиции среди всех регионов России. По данным на 2016 г., республика занимает 6 место среди всех регионов РФ по объему ВРП (валового регионального продукта), 3 место по объему инвестиций в основной капитал, 4 место по объему сельскохозяйственного производства и 5 место по объему промышленного производства и строительства [16]. Следующей по объему ВРП является Самарская область, остальные регионы (из числа рассмотренных) существенно уступают им, характеризуясь объемами ВРП менее 1 трлн рублей.

Для выявления эффекта декаплинга в развитии Республики Татарстан были проанализированы статистические данные по экономическому развитию региона и сопутствующему воздействию на окружающую среду. Анализ имеющихся данных показал, что в период с 2011 по 2016 г. рост производства в республике сопровождался разнонаправленными тенденциями в изменении нагрузки на среду. Так, при увеличении ВРП (в текущих ценах) с 1,31 до 1,94 трлн рублей за тот же период выросли показатели выбросов в атмосферный воздух (с 277,9 до 289,6 тыс. тонн в год), а суммарный забор воды из водных объектов увеличился с 767,0 до 879,4 млн м ${ }^{3}$ в период с 2011 по 2015 г. [5; 10]. При этом показатель доли загрязненных вод в общем объеме сброшенных вод сократился с 479,9 млн м ${ }^{3}$ в 2011 г. до 325,5 млн м ${ }^{3}$ в 2016 году.

Таким образом, следует отдельно рассматривать выявление эффекта декаплинга по отношению к различным видам воздействия на окружающую среду в процессе экономического развития, принимая во внимание приоритетные для региона отрасли экономики, соответствующие им виды природопользования и преобладающий характер воздействия на окружающую среду. На примере Респуб-

Таблица 1

\section{Социально-экономические характеристики региона исследования}

\begin{tabular}{|l|c|c|r|}
\hline \multicolumn{1}{|c|}{ Субъект Федерации } & $\begin{array}{c}\text { Площадь, } \\
\text { тыс. км }^{2}\end{array}$ & $\begin{array}{c}\text { Население, } \\
\text { тыс. чел. }\end{array}$ & $\begin{array}{c}\text { ВРП, } \\
\text { млн руб. }\end{array}$ \\
\hline Республика Марий Эл & 23,4 & 685,9 & 165531,0 \\
\hline Республика Татарстан & 67,8 & 3868,7 & 1833214,5 \\
\hline Чувашская Республика & 18,3 & 1236,6 & 250408,9 \\
\hline Самарская область & 53,6 & 3206,0 & 1240319,8 \\
\hline Ульяновская область & 37,2 & 1257,6 & 301424,7 \\
\hline
\end{tabular}

Примечание. Составлено по: [16; 17]. 
лики Татарстан и соседних с ней регионов Поволжья эффект декаплинга оценивался за период с 2011 по 2015 г. по сопоставлению объема ВРП и выбросов в атмосферный воздух от стационарных источников. Показатель объема выбросов в атмосферный воздух отражает степень антропогенной нагрузки в силу корреляции с уровнем развития промышленного производства, структурой экономики и характером преобладающих экологических проблем, поэтому такой подход представляется обоснованным.

Одной из основных проблем регионов Поволжья, как и большинства индустриально развитых регионов Российской Федерации, является загрязнение атмосферного воздуха. Анализ динамики состояния воздуха в крупных городах Татарстана и соседних регионов демонстрирует похожие результаты. Так, в период с 2011 по 2016 г. в таких городах Татарстана, как Казань, Набережные Челны, Нижнекамск и др. отмечено увеличение загрязнения воздуха. В Казани, например, выбросы загрязняющих веществ увеличились с 102,8 до 107,3 тыс. т, в Нижнекамске - с 76,2 до 103,5 тыс. т в год [5]. Рост количества выбросов зафиксирован и в целом по Татарстану. При этом в других регионах при увеличении объемов ВРП отмечается снижение выбросов в атмосферный воздух, что отражает величина коэффициента декаплинга (табл. 2).

Отметим, что в принятом за год отсчета 2011 г. в большинстве крупных городов рассматриваемых регионов отмечался высокий уровень загрязнения воздуха. Так, в городах Чебоксары и Новочебоксарск (Республика Чувашия) индекс загрязнения атмосферы (ИЗА) составлял, соответственно, 13,1 и 13,9; фиксировалось превышение ПДК по бенз(а)пирену в 1,8 и 1,6 раз соответственно [8]. В Самарской области ИЗА соответствовал высокому уровню загрязнения в городах Самара, Сызрань, Тольятти [3]. В то же время в течение всего периода стабильно удовлетворительная ситуация наблюдалась в Республике Марий Эл, где среднегодовые концентрации загрязняющих веществ в воздухе не превышали ПДК, а значения ИЗА в городах Йошкар-Ола и Волжск не только соответствовали низкому уровню, но и демонстрировали тенденцию к снижению [11]. Для Самарской области, напротив, улучшение ситуации было минимальным, поскольку содержание основных загрязняющих веществ (диоксид азота, фенол, аммиак, формальдегид и др.) в воздухе промышленных городов (Самара, Сызрань, Тольятти) снизилось незначительно. Более того, опыт этого региона показывает, что фиксация улучшения состояния среды может быть обусловлена не столько снижением воздействия, сколько изменением нормативов ПДК. В 2011 г. ИЗА в промышленных городах области соответствовал высокому уровню, и к 2015 г., согласно данным [4], этот уровень загрязнения сохранялся в городах Самара и Отрадное, повышенный - в Сызрани, Тольятти и Новокуйбышевске. Однако в соответствии с новыми нормативами ПДК по ряду веществ, в том числе фенолу и формальдеги-

Таблича 2

Динамика показателей экономического развития и нагрузки на окружающую среду в регионах Поволжья в период с 2011 по 2015 г.

\begin{tabular}{|l|c|c|c|}
\hline \multicolumn{1}{|c|}{ Регионы } & $2011 *$ & $2015 *$ & $\begin{array}{c}\text { Коэффициент } \\
\text { декаплинга }\end{array}$ \\
\hline Республика Марий Эл & $\frac{96,6}{29}$ & $\frac{165,5}{22}$ & 0,56 \\
\hline Республика Татарстан & $\frac{1310}{278}$ & $\frac{1833}{294}$ & 0,25 \\
\hline Чувашская Республика & $\frac{188,4}{28}$ & $\frac{250,4}{27}$ & 0,28 \\
\hline Самарская область & $\frac{832,6}{292}$ & $\frac{1240}{261}$ & 0,4 \\
\hline Ульяновская область & $\frac{223,4}{42}$ & $\frac{260,3}{33}$ & 0,33 \\
\hline
\end{tabular}

Примечания. * - в числителе - величина ВРП, млрд рублей; в знаменателе - выбросы в атмосферный воздух от стационарных источников, тыс. тонн. Составлено по данным: [16; 17$]$. 
ду, уровень загрязнения в этих городах в документах официальной статистики характеризовался как низкий.

\section{Обсуждение результатов \\ и перспективы использования показателя декаплинга}

Полученные результаты (см. табл. 2) позволяют сделать вывод о наличии эффекта декаплинга в Татарстане и во всех рассматриваемых регионах Поволжья. При этом более детальное рассмотрение ситуации подтверждает предположение о том, что на формирование трендов развития влияют разные, иногда противоположные, факторы. Так, несмотря на увеличение выбросов в атмосферный воздух в целом по Республике Татарстан, для региона характерно наличие эффекта декаплинга, что обусловлено существенным (почти на 40 \%) ростом ВРП. Аналогичная величина в Чувашской Республике достигается при меньшем росте ВРП (33\%) и незначительном снижении выбросов. Отметим, что динамика выбросов в регионе весьма неравномерна: в период с 2011 по 2013 г. отмечался рост выбросов в атмосферный воздух, а в 20142015 гг. этот показатель оставался почти неизменным. Кроме того, объемы выбросов 2016 г. превышают показатель за 2011 год. Динамика коэффициента декаплинга по этому показателю в течение исследуемого периода приведена в таблице 3.

Таким образом, величина коэффициента может значительно варьироваться от года к году, принимая в том числе отрицательные значения. Однако эффект декаплинга отмечается для Республики Татарстан и по результатам расчетов на основании данных об использовании водных ресурсов: с учетом сбросов в водные объекты за период с 2011 по 2016 г. также получено положительное значение $\left(D_{t}=0,28\right)$.
Отдельного рассмотрения заслуживает колебание величины декаплинга на уровне административных районов республики. Результаты оценки по районам Республики Татарстан свидетельствуют о различиях в динамике и ВТП (валового территориального продукта), и объемов выбросов в атмосферный воздух [10; 13]. Причем, если величина ВТП показывает в течение исследуемого периода временами незначительный, но все же стабильный рост (в текущих ценах), то показатели выбросов колеблются весьма существенно, порой скачкообразно, резко сокращаясь за счет увеличения затрат на природоохранные технологии или возрастая в результате введения новых производственных мощностей. Расчеты коэффициента декаплинга для районов Татарстана были проведены за период с 2011 по 2015 г., дифференциация величин показана на рисунке.

В 12 из 43 районов Татарстана коэффициент декаплинга имеет отрицательное значение, в остальных - положительное, что говорит не только о разном уровне организации природоохранной деятельности, включая финансирование этой сферы, но и о необходимости дальнейшего анализа полученных результатов. Очевидно, что величина коэффициента может варьироваться в зависимости от выбора показателей нагрузки на окружающую среду: в зависимости от преобладающего в районе вида природопользования это могут быть не только показатели выбросов загрязняющих веществ в атмосферный воздух или сбросов в водные объекты, но также динамика площади эродированных земель, лесистости территории, образования коммунальных и производственных отходов и т. п. [12]. Тем не менее использование выбранного подхода представляется вполне обоснованным, так как выбросы в атмосферный воздух формируются за счет как стационарных, так и мобильных источников, а их объемы отражают ин-

Таблича 3

Динамика коэффициента декаплинга по Республике Татарстан в период с 2011 по 2016 г.

\begin{tabular}{|l|c|c|c|c|c|c|}
\hline \multicolumn{1}{|c|}{ Годы } & 2011 & 2012 & 2013 & 2014 & 2015 & 2016 \\
\hline $\begin{array}{l}\text { Коэффициент } \\
\text { декаплинга }\end{array}$ & 0,2 & 0,05 & 0,05 & 0,11 & 0,06 & $-0,06$ \\
\hline
\end{tabular}

Примечание. Составлено авторами по данным: [16;17]. 


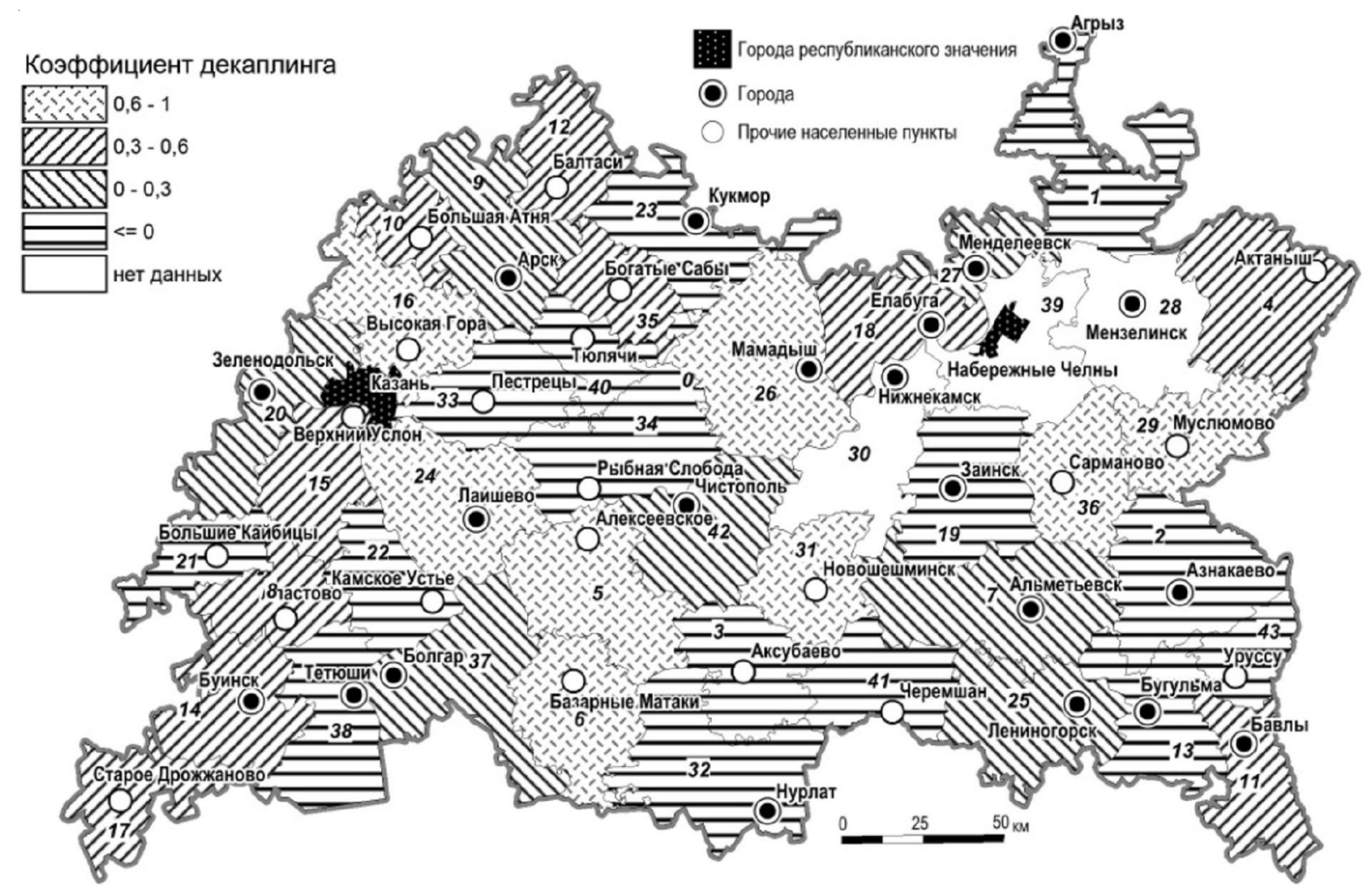

Рисунок. Величина коэффициента декаплинга по районам Татарстана (цифрами на карте обозначены муниципальные районы Республики Татарстан):

1 - Агрызский; 2 - Азнакаевский; 3 - Аксубаевский; 4 - Актанышский; 5 - Алексеевский; 6 - Алькеевский;

7 - Альметьевский; 8 - Апастовский; 9 - Арский; 10 - Атнинский; 11 - Бавлинский; 12 - Балтасинский;

13 - Бугульминиский; 14 - Буинский; 15 - Верхнеуслонский; 16 - Высокогорский; 17 - Дрожжановский;

18 - Елабужский; 19 - Заинский; 20 - Зеленодольский; 21 - Кайбицкий; 22 - Камско-Устьинский; 23 - Кукморский;

24 - Лаишевский; 25 - Лениногорский; 26 - Мамадышский; 27 - Менделеевский; 28 - Мензелинский;

29 - Муслюмовский; 30 - Нижнекамский; 31 - Новошешминский; 32 - Нурлатский; 33 - Пестречинский;

34 - Рыбно-Слободский; 35 - Сабинский; 36 - Сармановский; 37 - Спасский; 38 - Тетюшский; 39 - Тукаевский; 40 - Тюлячинский; 41 - Черемшанский; 42 - Чистопольский; 43 - Ютазинский

тенсивную хозяйственную деятельность вне зависимости от доли тех или иных отраслей в структуре экономики. Следует особо отметить, что использование коэффициента декаплинга для оценки устойчивости развития открывает в дальнейшем перспективы для работ методического характера: предложения по классификации показателей декаплинга для разных видов природопользования будут способствовать формированию методики оценки устойчивости на региональном уровне.

\section{Заключение}

Анализ эффекта декаплинга представляется актуальным, поскольку позволяет учесть не только эколого-экономические, но и социальные аспекты развития. Очевидно, что по- казатель декаплинга отражает тенденции в изменении состояния окружающей среды, сопровождающие экономический рост, что в значительной степени влияет на качество жизни населения в ближайшей и отдаленной перспективах. Показатель декаплинга может рассматриваться и в контексте обеспечения справедливого распределения благ (как между странами и регионами, так и между поколениями). Такой подход фактически был использован в работе [21], где региональный анализ антропогенного воздействия основывался не только на соотношении ресурсов на «входе» и «выходе» производственной цепочки, но также на учете конечного потребления произведенной продукции.

Применение подхода на основе коэффициента декаплинга может иметь более широ- 
кие перспективы в контексте измерения устойчивости развития. Тренды развития региональной экономики можно рассматривать с учетом изменения природоемкости (или энергоемкости как одного из ее проявлений) производства либо природопользования в целом. В перспективе на этом же принципе могут быть основаны оценки, включающие индикаторы социальных процессов, такие как занятость населения, уровень социального обеспечения и т. п., что позволит разрабатывать рекомендации по развитию регионального природопользования в соответствии с принципами устойчивого развития.

\section{ПРИМЕЧАНИЕ}

${ }^{1}$ Статья подготовлена в рамках гранта РФФИ «Теоретико-методологические основы устойчивого развития регионов России (на примере регионов Поволжья)», проект № 17-02-00773.

\section{СПИСОК ЛИТЕРАТУРЫ}

1. Акулов, А. О. Эффект декаплинга в индустриальном регионе (на примере Кемеровской области) / А. О. Акулов // Экономические и социальные перемены: факты, тенденции, прогноз. 2013. - № 4 (28). - С. 177-185.

2. Бобылев, С. Н. Устойчивое развитие: методология и методики измерения / С. Н. Бобылев, Н. В. Зубаревич, С. В. Соловьева, Ю. С. Власов ; под ред. С. Н. Бобылева. - М. : Экономика, 2011. -358 с.

3. Государственный доклад о состоянии окружающей среды и природных ресурсов Самарской области за 2011 год. - Самара, 2012. - Вып. 22. -336 с.

4. Государственный доклад о состоянии окружающей среды и природных ресурсов Самарской области за 2015 год. - Самара, 2016. - Вып. 26. 296 c.

5. Государственный доклад о состоянии природных ресурсов и об охране окружающей среды Республики Татарстан (за 2011 и 2016 г.) // Официальный сайт Министерства природных ресурсов и экологии Республики Татарстан. - Электрон. текстовые дан. - Режим доступа: http://eco.tatarstan.ru/ gosdoklad.htm (дата обращения: 12.11.2017). - Загл. с экрана.

6. Доклад о человеческом развитии в Российской Федерации за 2015 год / под ред. Л. М. Григорьева, С. Н. Бобылева. - М. : Аналитический центр при Правительстве Российской Федерации, 2015. $260 \mathrm{c}$.
7. Доклад о человеческом развитии в Российской Федерации за 2016 год / под ред. С. Н. Бобылева, Л. М. Григорьева. - М. : Аналитический центр при Правительстве Российской Федерации, 2016. 298 c.

8. Доклад об экологической ситуации в Чувашской Республике в 2015 году. - Чебоксары : Министерство природных ресурсов и экологии, 2016. $-76 \mathrm{c}$.

9. На пути к устойчивому развитию России. «Зеленая» экономика и модернизация. Экологоэкономические основы устойчивого развития / под ред. В. М. Захарова. - М. : Ин-т устойчивого развития, 2012. $-90 \mathrm{c}$.

10. Основные показатели социально-экономического развития Республики Татарстан в 2016 году // Официальный сайт Министерства экономики Республики Татарстан. - Электрон. текстовые дан. Режим доступа: http://mert.tatarstan.ru/rus/file/pub/ pub_857445.pdf(дата обращения: 03.10.2017). - Загл. с экрана.

11. Официальная статистика. Валовой региональный продукт // Территориальный орган Федеральной службы государственной статистики по Республике Марий Эл. - Электрон. текстовые дан. Режим доступа: http://maristat.gks.ru/wps/wcm/ connect/rosstat_ts/maristat/ru/statistics/grp/ (дата обращения: 05.10.2017). - Загл. с экрана.

12. Пакина, А. А. Эколого-экономические аспекты измерения устойчивости развития на региональном уровне / А. А. Пакина, Н. И. Тульская // Рациональное природопользование: традиции и инновации : материалы II Междунар. конф. / под общ. ред. проф. М. В. Слипенчука. - М. : Изд-во КДУ, 2017. - С. 263-267.

13. Портал муниципальных образований Республики Татарстан. - Электрон. текстовые дан. Режим доступа: http://msu.tatarstan.ru/rus/mregions. htm (дата обращения: 21.10.2017). - Загл. с экрана.

14. Республика Татарстан 2016. Статистический справочник // Территориальный орган Федеральной службы государственной статистики по Республике Татарстан. - Казань, 2016. - Электрон. текстовые дан. - Режим доступа: http://tatstat. gks. $\mathrm{ru} / \mathrm{wps} / \mathrm{wcm} /$ connect/rosstat_ts/tatstat/resources/ $76514880443 \mathrm{~b} 4$ aa3ab78ef20d5236cbc/Стат + справочник,+2016+.pdf (дата обращения: 28.09.2017). - Загл. с экрана.

15. Салмина, А. Избыточное неравенство и развитие человеческого потенциала / А. Салмина // Доклад о человеческом развитии в Российской Федерации. - М. : Аналитический центр при Правительстве Российской Федерации, 2014. - С. 84-105.

16. Федеральная служба государственной статистики. Регионы России. Социально-экономические показатели - 2016. Валовой региональный про- 
дукт. - Электрон. текстовые дан. - Режим доступа: http://www.gks.ru/bgd/regl/b16_14p/Main.htm (дата обращения: 08.12.2017). - Загл. с экрана.

17. Федеральная служба государственной статистики. Регионы России. Социально-экономические показатели - 2016. Окружающая среда. - Электрон. текстовые дан. - Режим доступа: gks.ru/ free_doc/new_site/vvp/vrp98-15.xlsx (дата обращения: 08.12.2017). - Загл. с экрана.

18. Шкиперова, Г. Т. Анализ и моделирование взаимосвязи между экономическим ростом и качеством окружающей среды (на примере Республики Карелия) / Г. Т. Шкиперова // Экономический анализ: теория и практика. - 2014. - № 43 (394). C. $41-49$.

19. Decoupling environmental pressure from economic growth on city level: the case study of Chongqing in China / Y. Yu, L. Zhou, W. Zhou [et al.] // Ecological Indicators. - 2014. - № 37. - P. 81-89.

20. Sustainable development. Knowledge platform. 2030 Agenda for Sustainable Development // Официальный сайт Организации Объединенных Наций (OOH). - Электрон. текстовые дан. - Режим доступа: https://sustainabledevelopment.un.org/ content/documents/21252030\%20Agenda $\% 20$ for $\% 20$ Sustainable\%20Development\%20web.pdf (дата обращения: 15.12.2017). - Загл. с экрана.

21. The Global Resource Footprint of Nations. Carbon, water, land and materials embodied in trade and final consumption calculated with EXIOBASE 2.1. /A. Tukker, T. Bulavskaya, S. Giljum [et al.]. - Leiden ; Delft ; Vienna ; Trondheim, 2014.-72 p.

22. UNEP's Green Economy Initiative (GEI) // Официальный веб-сайт Программы по окружающей среде Организации Объединенных Наций. Электрон. текстовые дан. - Режим доступа: https:// www.unep.org/greeneconomy/ (дата обращения: 10.09.2017). - Загл. с экрана.

\section{REFERENCES}

1. Akulov A.O. Effekt dekaplinga v industrialnom regione (na primere Kemerovskoy oblasti) [Decoupling Effect in the Industrial Region]. Ekonomicheskie i sotsialnye peremeny: fakty, tendentsii, prognoz, 2013, no. 4 (28), pp. 177-185.

2. Bobylev S.N., Zubarevich N.V., Solovyeva S.V., Vlasov Yu.S. Ustoychivoe razvitie: metodologiya $i$ metodiki izmereniya [Sustainable Development: Methodology and Techniques of Measurement]. Moscow, Ekonomika Publ., 2011.358 p.

3. Gosudarstvennyy doklad o sostoyanii okruzhayushchey sredy i prirodnykh resursov Samarskoy oblasti za 2011 god. Vypusk 22 [State Report on the Condition of Environment and Natural
Resources of the Samara Region for 2011. Iss. 22]. Samara, 2012.336p.

4. Gosudarstvennyy doklad o sostoyanii okruzhayushchey sredy $i$ prirodnykh resursov Samarskoy oblasti za 2015 god. Vypusk 26 [State Report on the Condition of Environment and Natural Resources of the Samara Region for 2015. Iss. 26]. Samara, 2016. 296 p.

5. Gosudarstvennyy doklad o sostoyanii prirodnykh resursov i ob okhrane okruzhayushchey sredy Respubliki Tatarstan (za 2011 i 2016 gg.) [State Report on the Natural Resources and Environment Protection of the Republic of Tatarstan (for 2011 and 2016)]. Ofitsialnyy sayt Ministerstva prirodnykh resursov $i$ ekologii Respubliki Tatarstan [Official Website of the Ministry of Natural Resources and Ecology of the Republic of Tatarstan]. URL: http://eco.tatarstan.ru/gosdoklad.htm. (accessed November 12, 2017).

6. Grigoryev L.M., Bobylev S.N., eds. Doklado chelovecheskom razvitii $v$ Rossiyskoy Federatsii za 2015 god [The Report on Human Development in the Russian Federation for 2015]. Moscow, Analiticheskiy tsentr pri Pravitelstve Rossiyskoy Federatsii, 2016. $260 \mathrm{p}$.

7. Grigoryev L.M., Bobylev S.N., eds. Doklado chelovecheskom razvitii $v$ Rossiyskoy Federatsii za 2016 god [The Report on Human Development in the Russian Federation for 2016]. Moscow, Analiticheskiy tsentr pri Pravitelstve Rossiyskoy Federatsii, 2017. $298 \mathrm{p}$.

8. Doklad «Ob ekologicheskoy situatsii v Chuvashskoy Respublike v 2015 godu»: Monografiya [The Report "On Environmental Situation in the Chuvash Republic in 2015". Monograph]. Cheboksary, Min-vo prirodnykh resursov i ekologii, 2016. 76 p.

9. Zakharov V.M., ed. Na puti $k$ ustoychivomu razvitiyu Rossii. "Zelenaya ekonomika $i$ modernizatsiya. Ekologo-ekonomicheskie osnovy ustoychivogo razvitiya [On the Way Towards Sustainable Development of Russia. "Green" Economy and Modernization. Ecological and Economic Foundations of Sustainable Development]. Moscow, In-t ustoychivogo razvitiya, $2012.90 \mathrm{p}$.

10. Osnovnye pokazateli sotsialnoekonomicheskogo razvitiya Respubliki Tatarstan v 2016 godu [Basic Indicators of Socio-Economic Development of the Republic of Tatarstan in 2016]. Ofitsialnyy sayt Ministerstva ekonomiki Respubliki Tatarstan [Official Website of the Ministry of the Republic of Tatarstan]. URL: http://mert.tatarstan.ru/ rus/file/pub/pub_857445.pdf. (accessed October 3, 2017).

11. Ofitsialnaya statistika. Valovoy regionalnyy produkt. Territorialnyy organ Federalnoy sluzhby gosudarstvennoy statistiki po Respublike Mariy El [Official Statistics. Gross Domestic Product. Territorial 
Body of the Federal Service of the State Statistics in Mari El Republic]. URL: http://maristat.gks.ru/wps/ $\mathrm{wcm} /$ connect/rosstat_ts/maristat/ru/statistics/grp/. (accessed October 5, 2017).

12. Pakina A.A., Tulskaya N.I. Ekologoekonomicheskie aspekty izmereniya ustoychivosti razvitiya na regionalnom urovne [Ecological and Economic Aspects of Sustainable Development Measurement at the Regional Level]. Slipenchuk M.V., ed. Ratsionalnoe prirodopolzovanie: traditsii $i$ innovatsii. Materialy II Mezhdunarodnoy konferentsii [Rational Nature Management: Traditions and Innovations. Proceedings of the $2^{\text {nd }}$ International Conference]. Moscow, KDU Publ., 2017, pp. 263-267.

13. Portal munitsipalnykh obrazovaniy Respubliki Tatarstan [Portal of Municipalitites of the Republic of Tatarstan]. URL: http://msu.tatarstan.ru/ rus/mregions.htm. (accessed October 21, 2017).

14. Respublika Tatarstan 2016. Statisticheskiy spravochnik. Territorialnyy organ Federalnoy sluzhby gosudarstvennoy statistiki po Respublike Tatarstan [Republic of Tatarstan 2016. Statistical Handbook. Territorial Body of the Federal Service of State Statistics in the Republic of Tatarstan]. Kazan, 2016. URL: http://tatstat.gks.ru/wps/wcm/connect/ rosstat_ts/tatstat/resources/76514880443b4aa3ab78 ef20d5236cbc/Стат+справочник,+2016+.pdf. (accessed September 28, 2017).

15. Salmina A. Izbytochnoe neravenstvo i razvitie chelovecheskogo potentsiala [Excessive Inequality and Development of Human Potential]. Doklad o chelovecheskom razvitii $v$ Rossiyskoy Federatsii [The Report on Human Development in the Russian Federation]. Moscow, Analiticheskiy tsentr pri Pravitelstve Rossiyskoy Federatsii, 2014, pp. 84-105.

16. Federalnaya sluzhba gosudarstvennoy statistiki. Regiony Rossii. Sotsialno-ekonomicheskie pokazateli - 2016. Valovoy regionalnyy product
[Federal Service of State Statistics. Regions of Russia. Socio-Economic Indicators - 2016. Gross Regional Product]. URL: http://www.gks.ru/bgd/regl/b16_14p/ Main.htm. (accessed December 8, 2017).

17. Federalnaya sluzhba gosudarstvennoy statistiki. Regiony Rossii. Sotsialno-ekonomicheskie pokazateli - 2016. Okruzhayushchaya sreda [Federal Service of State Statistics. Regions of Russia. SocioEconomic Indicators - 2016. Environment]. URL: gks.ru/ free_doc/new_site/vvp/vrp98-15.xlsx. (accessed December 8, 2017).

18. Shkiperova G.T. Analiz i modelirovanie vzaimosvyazi mezhdu ekonomicheskim rostom i kachestvom okruzhayushchey sredy (na primere Respubliki Kareliya) [Analysis and modelling of relationship between economical growth and quality of environment]. Ekonomicheskiy analiz: teoriya $i$ praktika, 2014, no. 43 (394). P.41-49.

19. Yu Y., Zhou L., Zhou W., Ren H., Kharrazi A., Ma T., Zhu B. Decoupling environmental pressure from economic growth on city level: the case study of Chongqing in China. Ecological Indicators, 2014, vol. 37, pp. 81-89.

20. Sustainable development. Knowledge platform. 2030 Agenda for Sustainable Development. Official Website of the United Nations Organisation. URL: https://sustainabledevelopment.un.org/content/ documents $/ 21252030 \% 20$ Agenda $\% 20$ for $\%$ 20 Sustainable\%20Development\%20web.pdf. (accessed December 15, 2017).

21. Tukker, A., Bulavskaya, T., Giljum, S., de Koning, A., Lutter, S., Simas, M., Stadler, K., Wood, R. The Global Resource Footprint of Nations. Carbon, water, land and materials embodied in trade and final consumption calculated with EXIOBASE 2.1. Leiden/ Delft/Vienna/Trondheim, 2014. 72 p.

22. UNEP's Green Economy Initiative (GEI). Official Website of the United Nations Organisation. URL: https://www.unep.org/greeneconomy/. (accessed September 10, 2017).

\section{Information about the Authors}

Sergey N. Kirillov, Doctor of Sciences (Economics), Professor, Department of Rational Nature Management, Lomonosov Moscow State University, Leninskie gory, 1, 119991 Moscow, Russian Federation, eco-msu@mail.ru.

Alla A. Pakina, Candidate of Sciences (Geography), Associate Professor, Leading Researcher, Department of Rational Nature Management, Lomonosov Moscow State University, Leninskie gory, 1, 119991 Moscow, Russian Federation, allapa@yandex.ru.

Nadezhda I. Tulskaya, Candidate of Sciences (Geography), Associate Professor, Department of Cartography and Geoinformatics, Lomonosov Moscow State University, Leninskie gory, 1, 119991 Moscow, Russian Federation, tnadya@mail.ru. 


\section{Информация об авторах}

Сергей Николаевич Кириллов, доктор экономических наук, профессор кафедры рационального природопользования, Московский государственный университет им. М.В. Ломоносова, Ленинские горы, 1, 119991 г. Москва, Российская Федерация, есо-msu@mail.ru.

Алла Анатольевна Пакина, кандидат географических наук, доцент, ведущий научный сотрудник кафедры рационального природопользования, Московский государственный университет им. М.В. Ломоносова, Ленинские горы, 1, 119991 г. Москва, Российская Федерация, allapa@yandex.ru.

Игоревна Тульская Надежда, кандидат географических наук, доцент кафедры картографии и геоинформатики, Московский государственный университет им. М.В. Ломоносова, Ленинские горы, 1, 119991 г. Москва, Российская Федерация, tnadya@mail.ru. 